\title{
DELIBERATE SELF-POISONING IN SOUTH ODISHA: STUDY OF ITS CLINICAL PROFILE AND OUTCOME
}

\author{
SACHIDANANDA NAYAK, BIJAYA KUMAR BEHERA*, KESHABA CHANDRA BUDULA, SRITAM ACHARYA
}

Department of General Medicine, Maharaja Krishna Chandra Gajapati Medical College and Hospital, Berhampur, Odisha, India. Email: drbkbehera@gmail.com

Received: 17 March 2020, Revised and Accepted: 08 June 2020

\section{ABSTRACT}

Objective: Deliberate self-poisoning is a serious global issue that contributes to significant morbidity and mortality all over the world. The present study was conducted with an objective to identify the common agents used for self-poisoning prevalent in South Odisha and to determine the common clinical features and outcome of such cases.

Methods: This cross-sectional observational study was conducted on 200 patients with deliberate self-poisoning belonging to the age group of $15-70$ years over a period of 2 years from August 2017 to September 2019 in Maharaja Krishna Chandra Gajapati Medical College and Hospital, Berhampur, Odisha, India. All the above-mentioned patients admitted to the hospital, were treated with specific antidotes according to the poison ingested. Results were analyzed using appropriate standard statistical methods such as mean, standard deviation, and percentage.

Results: Out of 200 patients, majority were female $(65 \%, n=130)$ and $35 \%(n=70)$ were male; mean age was $38.9( \pm 16.8)$ years. Organophosphates, aluminum phosphide, glyphosate, organochlorines, and carbamates were the most common pesticides used as poisoning agents (74.5\%, $\mathrm{n}=149$ ) followed by plant poisons (7\%, $\mathrm{n}=14$ ) which included yellow oleander seed. Overall mortality in our study was $12.5 \%$.

Conclusion: Pesticides and plant poisons were the common agents used in our study for deliberate self-poisoning. Young persons, illiterates, and housewives were commonly involved in suicide attempts. Organophosphate caused majority of deaths.

Keywords: Deliberate self-poisoning, Pesticides, Organophosphates, Plant poisons

(C) 2020 The Authors. Published by Innovare Academic Sciences Pvt Ltd. This is an open access article under the CC BY license (http://creativecommons. org/licenses/by/4. 0/) DOI: http://dx.doi.org/10.22159/ajpcr.2020.v13i8.38358

\section{INTRODUCTION}

Deliberate self-poisoning and suicides are serious global health issue in many developing and underdeveloped countries including India, where the toxicity of available poisons and sparse medical facilities contributes to significant morbidity and mortality.

It is also observed that suicide attempts by females are 3 times more common than males [1]. In India, social and economic reasons are the major cause of suicidal death in men while emotional and personal problems are the causes in women [2]

Profile of patients and their choice of agents depend on the local availability of the substances and the socioeconomic and cultural backgrounds. It is seen to vary in different regions [3].

Acute pesticide poisoning is a major issue in developing countries of the Asia-Pacific region and organophosphates are considered the most important cause of death from acute poisoning worldwide. In developed countries, however, the incidence of severe pesticide poisoning is relatively very low where drugs play the predominant role. According to data available from National Poison Information Centre, India, suicidal poisoning with pesticides is the most common modality of poisoning since it is cheap, highly toxic, and capable of being taken along with food or drink and above all easily available [4]

The WHO estimates that deliberate ingestion of pesticides causes 370,000 deaths each year which is one-fifth of the total world's suicidal deaths. The number of these deaths can be reduced by limiting the availability of and access to, highly toxic pesticides.

\section{Aims and objectives}

The aim of the present study was to determine the clinical profile and outcome of deliberate self-poisoning in South Odisha.

The objectives were:

- To study the demographic details of the patients of poisoning,

- To identify the common agents used for poisoning and

- To determine the common clinical features, complications, and outcomes of the patients treated.

\section{METHODS}

We designed a cross-sectional observational study which was conducted in the Department of General Medicine, Maharaja Krishna Chandra Gajapati Medical College and Hospital, Berhampur, Odisha, India, over a period of 2 years from August 2017 to September 2019. A total number of 200 patients of deliberate self-poisoning, belonging to the age group of 15-70 years of both the genders were taken from the Emergency Department, General Medicine Wards and Medical intensive care unit (ICU). The study was conducted after the study protocol was approved by the Institutional Ethics Committee. Informed consent was obtained either from the patients or from their relatives.

The types of poison were confirmed from patient's detailed history, signs and symptoms, reliable information, either from the patients or from his/her relatives, and the container of the poison produced.

Data regarding demographic profiles including age, sex, educational level, socioeconomic status, and premorbid conditions were recorded from them. 
Gastric lavage was done in most of the cases and gastric content samples were preserved and sent to forensic laboratory for chemical analysis, for medicolegal purpose.

All patients were investigated with routine and specific laboratory tests including baseline investigations such as complete blood count, serum urea, serum creatinine, random blood sugar, liver function tests, arterial blood gas analysis, electrocardiography (ECG), X-ray chest and plasma cholinesterase level, and other relevant tests at the time of admission.

Necessary therapeutic intervention was started as per standard protocol initially in the emergency ward. The patients requiring ICU care were shifted to medical ICU. Complications developed by the patients were recorded and were followed up until recovery or death. All the recovered deliberate self-poisoning patients were sent for psychiatric consultation and evaluation before their discharge from the hospital.

\section{Patients' selection criteria}

Patients with a history of deliberate self-poisoning of either sex and above 14 years of age admitted to the hospital were included in this study.

\section{Exclusion criteria}

Accidental exposure/ingestion of poison, drink spiking poisoning, psychiatric illness, snake bite, insect bite, food poisoning, and allergic reaction to drugs were excluded from this study.

\section{Statistical analysis}

Results were analyzed using appropriate standard statistical method such as mean ( \pm standard deviation $[\mathrm{SD}]$ ), and percentage.

\section{RESULTS}

\section{Demographics of participants}

Out of the 200 patients studied, 70 (35\%) were male and 130 (65\%) were female. Mean $( \pm$ SD) age of the study population was $38.9( \pm 16.8)$ years. Nineteen ( 1 male and 18 females) patients were adolescents, 146 (55 males and 91 females) were young, 31 (11 males and 20 females) were middle aged, and 4 (3 males and 1 female) were the elderly (Table 1). Occupation wise poisoning was found mostly among housewives in $85(42.5 \%)$ cases (Table 2) and education wise the incidence was seen in illiterates in 77 (38.5\%) cases (Table 3).

\section{Agents used}

Organophosphates, organochlorines, carbamates, aluminum phosphide, glyphosate, cypermethrin, and norbormide were the most common pesticides used as poisoning agents $(74.5 \%, \mathrm{n}=149)$ followed by plant poison $(7 \%, \mathrm{n}=14)$ which was yellow oleander seed. Toilet cleaning agents (phenol) $(6.5 \%, \mathrm{n}=13)$, drugs (benzodiazepines) $(6.5 \%, \mathrm{n}=13)$, supervasmol keshkala (paraphenylenediamine) $(2 \%, n=4)$, corrosive acid $(1 \%, n=2)$, kerosene (paraffin) $(1 \%, n=2)$, vermilion (mercury sulfide) $(0.5 \%, n=1)$, and unknown $(1 \%, n=2)$ were the other common poisoning agents (Table 4 )

Among pesticide poisoning cases, 91 were of organophosphates, 25 were of aluminum phosphide, 13 were of cypermethrin, 2 were of carbamate, and 4 were of organochlorine cases.

\section{Organophosphate poisoning}

In our study, the most commonly used organophosphate compounds were Chlorpyriphos (+cypermethrin) ( $n=43 ; 46.2 \%)$, followed by diamethoate $(n=29,31.8 \%)$, monochrotophus $(n=11,12.08 \%)$, and triazophos (+Deltamethrin) $(n=8,8.7 \%)$. Muscarinic features such as diarrhea, bradycardia, miosis, bronchorrhea and wheezing, nausea, vomiting, salivation, and hypotension were observed.

Nicotinic features such as fasciculation and tachycardia muscle weakness leading paralysis were seen. Central nervous system (CNS) features observed were altered sensorium and seizure.
The signs, symptoms, and complications of this cholinergic insecticide group with their number and percentage found in our study are shown in Table 5.

Organophosphate poisoning accounted for the majority of deaths $(n=19,82.60 \%)$, among the pesticide groups where total deaths due to pesticide were 23 (Table 4 ).

Table 1: Age and sex distribution of cases

\begin{tabular}{|c|c|c|c|}
\hline \multirow[t]{2}{*}{ Age in years } & Male & Female & Combined \\
\hline & No. (\%) & No. (\%) & No. (\%) \\
\hline $14-17$ & $1(0.5)$ & $18(9)$ & $19(9.5)$ \\
\hline $18-40$ & $55(27.5)$ & $91(45.5)$ & $146(73)$ \\
\hline $41-60$ & $11(5.5)$ & $20(10)$ & 31 (15.5) \\
\hline$\geq 60$ & $3(1.5)$ & $1(0.5)$ & $4(2)$ \\
\hline Total & $70(35)$ & $130(65)$ & $200(100)$ \\
\hline
\end{tabular}

Table 2: Distribution of cases according to occupation

\begin{tabular}{lll}
\hline Sl. no. & Occupation & No. (\%) \\
\hline 1. & Housewife & $85(42.5)$ \\
2. & Laborers & $8(4)$ \\
3. & Students & $57(25.5)$ \\
4. & Farmers & $24(12)$ \\
5. & Business & $18(9)$ \\
6. & Workers & $14(7)$ \\
Total & & 200 \\
\hline
\end{tabular}

Table 3: Educational status of the study group

\begin{tabular}{ll}
\hline Educational status & No. of cases (\%) \\
\hline Illiterate & $77(38.5)$ \\
Primary & $57(28.5)$ \\
$10^{\text {th }}$ & $37(18.5)$ \\
Higher secondary & $15(7.5)$ \\
Graduate & $14(7)$ \\
Total & $200(100)$ \\
\hline
\end{tabular}

Table 4: Agents used for deliberate self-poisoning

\begin{tabular}{|c|c|c|}
\hline \multirow[t]{2}{*}{ Category } & $\begin{array}{l}\text { Number of } \\
\text { patients } \\
\text { admitted }\end{array}$ & $\begin{array}{l}\text { Number of } \\
\text { patients } \\
\text { expired }\end{array}$ \\
\hline & No. $(\%)$ & No. $(\%)$ \\
\hline Organophosphates $(a+b+c+d)$ & $91(45.5)$ & $19(9.5)$ \\
\hline (a) Chlorpyriphos + cypermethrin & $43(21.5)$ & $9(4.5)$ \\
\hline (b) Diamethoate & $29(14.5)$ & $3(1.5)$ \\
\hline (c) Monocrotophos & $11(5.5)$ & $4(2)$ \\
\hline (d) Triazophos +deltamethrin & $8(4)$ & $3(1.5)$ \\
\hline Organochlorine & $4(2)$ & $0(0)$ \\
\hline Carbamate & $2(1)$ & $0(0)$ \\
\hline Aluminum phosphide (rodenticide) & $25(12.5)$ & $2(1)$ \\
\hline Cypermethrin (insecticide) & $13(6.5)$ & $1(0.5)$ \\
\hline Norbormide (rodenticide) & $4(2)$ & $1(0.5)$ \\
\hline Glyphosate (herbicide) & $10(5)$ & $0(1)$ \\
\hline Yellow oleander & $14(7)$ & $0(0)$ \\
\hline Drugs (benzodiazepine) & $13(6.5)$ & $0(0)$ \\
\hline Toilet cleaning agent (phenol) & $13(6.5)$ & $0(0)$ \\
\hline Corrosive acid $\left(\mathrm{H}_{2} \mathrm{SO}_{4}\right)$ & $2(1)$ & $0(0)$ \\
\hline Kerosene (paraffin) & $2(1)$ & $0(0)$ \\
\hline Vermillon (mercury sulfide) & $1(0.5)$ & $0(0)$ \\
\hline Supervasmol (para phenylenediamine) & $4(2)$ & $0(0)$ \\
\hline Unknown & $2(1)$ & $0(0)$ \\
\hline Total & $200(100)$ & $25(12.5)$ \\
\hline
\end{tabular}


Table 5: Clinical features and complications of organophosphate poisoning cases

\begin{tabular}{ll}
\hline Clinical features and complications & $\begin{array}{l}\text { Number of } \\
\text { patients } \mathbf{n = 9 1 ( \% )}\end{array}$ \\
\hline Nausea & $86(94.5)$ \\
Vomiting & $86(94.5)$ \\
Bronchospasm & $40(43.5)$ \\
Altered sensorium & $30(32.9)$ \\
Pain abdomen & $45(49.4)$ \\
Giddiness & $40(43.9)$ \\
Seizure & $19(20.8)$ \\
Bradycardia & $85(93.4)$ \\
Diarrhea & $10(10.9)$ \\
Smell of kerosene/increase bronchial secretion & $90(98.9)$ \\
Oronasal frothing/salivation & $19(20.8)$ \\
Urinary incontinence & $50(54.94)$ \\
Miosis & $70(76.9)$ \\
Fasciculation & $9(9.8)$ \\
Diminished deep tendon reflexes & $9(9.8)$ \\
Tachycardia & $6(6.59)$ \\
Hypotension & $5(5.4)$ \\
Pulmonary edema/bronchorrhea & $10(10.9)$ \\
Complication & \\
Multiorgan failure & $10(10.98)$ \\
Intermediate syndrome & $6(6.59)$ \\
Respiratory failure & $12(13.1)$ \\
\hline
\end{tabular}

\section{Aluminum phosphide poisoning}

As there is no specific antidote for aluminum phosphide poisoning, patients were treated conservatively providing symptomatic and supportive aid.

Out of 25 patients of the above poisoning, vomiting was observed in $22(88 \%)$ patients followed by epigastric pain in $20(80 \%)$ patients. Hypotension in $6(24 \%)$ patients, restlessness in $6(24 \%)$, tachypnea in $8(32 \%)$ patients, and altered sensorium in $2(8 \%)$ patients were seen. Two patients developed supraventricular tachycardia and succumbed to death.

\section{Cypermethrin poisoning}

The following symptoms had been observed in cypermethrin poisoning patients. Out of 13 patients, 10 (76.9\%) patients exhibited facial burning and tingling. The other symptoms found were dizziness in 8 (61.5\%), nausea in $10(76.9 \%)$, headache in $8(61.5 \%)$, and seizure in $1(7.6 \%)$ cases. One patient died in this pesticide (insecticide) study group.

\section{Glyphosate poisoning}

The number of patients admitted in this pesticide (herbicide) group was 10 and they showed symptoms of nausea and vomiting in $9(90 \%)$ cases. The other clinical features such as erosion of gastrointestinal tract in $2(20 \%)$ cases, difficulty in swallowing in $3(30 \%)$ cases, hypotension in $2(20 \%)$ cases, dehydration in $3(30 \%)$ cases, pneumonitis in $2(20 \%)$ cases, altered level of consciousness in $2(20 \%)$ cases, and dysrhythmia in $2(20 \%)$ cases were found. Two patients died of this poisoning.

\section{Yellow oleander (Thevetia peruviana) poisoning}

Gastrointestinal symptoms observed in yellow oleander poisoning were vomiting in $10(71.4 \%)$ patients and abdominal pain in $4(28.5 \%)$ patients. CNS symptoms observed were drowsiness in 2 (14.2\%) patients and dizziness/syncope in 5 (35.7\%) patients. Cyclic vomiting syndrome symptoms found were palpitation in $5(35.7 \%)$ patients, bradycardia in $8(57.1 \%)$ patients, and hypotension in 1 (7.1\%) patient. ECG findings among 14 patients were sinus bradycardia in $8(57.1 \%)$ patients and first degree atrioventricular (AV) block in $6(42.8 \%)$ patients. Out of 14 patients of oleander poisoning, 4 (28.5\%) patients were asymptomatic and casualty was zero.

\section{Other poisonings}

Out of 13 benzodiazepine poisoning cases, $8(61.5 \%)$ patients were presented with drowsiness, 6 (46.1\%) with hypotonia, 6 (46.1\%) with bradycardia, 3 (23.07\%) with urinary incontinence, 3 (23.07\%) with diminished deep tendon reflexes, and $1(7.6 \%)$ with hypotension.

Phenol caused extensive local corrosions in $6(46.1 \%)$ patients, pain in $6(46.1 \%)$ patients, nausea and vomiting in $10(76.9 \%)$ patients, and sweating in $3(23.07 \%)$ patients.

Out of 4 paraphenylenediamine poisoning cases, 3 (75\%) patients were presented with symptoms of difficulty in swallowing. Three patients (75\%) with facial puffiness and edema of lips and 3 patients (75\%) with stridor and difficulty in speaking were found with this poisoning. In this study of other poisonings, there were no deaths found.

\section{Outcome}

The mortality in the present study was $12.5 \%$ (25 deaths with 17 males and 8 females).

All the above cases belonged to pesticide groups where 19 were due to organophosphate poisoning, 2 with glyphosate poisoning, 2 with aluminum phosphide poisoning, and one each with cypermethrin and norbormide poisoning (Table 4).

\section{DISCUSSION}

The objective of this study was to describe the demographic features, identifying the common agents used for deliberate self-poisoning, and assessment of common clinical features with outcomes.

This study shows the high incidence of deliberate self-poisoning among females, which is similar to studies done internationally [5-8] but contradicts the study done by Sharma et al. (2002), [9] Dash et al. (2005) [10], and Singh et al. (1984) [11] in India in which the incidence was high among males.

Maximum number of cases were in the age group of 18-40 years $(n=146,73 \%)$ which can be explained by the fact that the persons of this age group were victims of modern lifestyle, failure in love, family problems, nuclear family concept, etc. This result differs from a United States study where the rate was found to be higher in the age group of adolescents [6]. However, similar results were found in the United Kingdom [5] where the majority of deliberate self-poisoning patients were in their thirties.

The majority of patients of suicidal poisoning were housewives $(\mathrm{n}=85$, $42.5 \%)$ followed by students $(n=57,28.5 \%)$ and farmers $(n=24,12 \%)$ followed by businessmen ( $\mathrm{n}=18.9 \%)$ (Table 2). It could be due to domestic problems in case of housewives, whereas in case of students, stress of modern lifestyle, failure in love, and family pressure might be the cause. Poverty was the main cause of suicidal attempts in case of farmers, whereas business failure led the business men to attempt the same.

Educational status shows that maximum number of suicidal poisoning cases were from the groups of illiterates $(n=77,38.5 \%)$, whereas primary educated accounted for $28.5 \%(n=57)$. Thirty-seven $(18.5 \%)$ patients were secondary and $15(7.5 \%)$ patients were higher secondary educated. Only $7 \%(n=14)$ of patients were graduates. This result differs from other study groups like Singh et al. [12]. This study shows that pesticides were the most common agents used for deliberate selfpoisoning followed by plant poison, and in all the cases, the route of ingestion was oral. A similar study had been carried out by Madhavan et al. in South India [13].

Among pesticides, organophosphates were the common agents $(61.07 \%)$ unlike the other studies where carbamates were common, which may be due to regional variation [13]. A study from All India Institute of Medical Sciences, New Delhi, also showed a predominance of carbamates among pesticide group, but poisoning due to drugs predominated that study [14]. Organophosphate compounds inactivate acetylcholinesterase (AChE), resulting in the accumulation of acetylcholine (ACh) and uncontrolled activation of cholinergic 
synapses. Clinical manifestations of organophosphate poisoning include cholinergic syndromes, CNS, and cardiovascular disorders. In our study, we found cholinergic symptoms of both muscarinic and nicotinic features such as diarrhea, miosis, bradycardia, bronchorrhea, bronchoconstriction, emesis, salivation, hypotension, and fasciculation.

Standard treatment was given to reduce absorption with gastric lavage and/or activated charcoal and continued with administration of atropine and pralidoxime. Atropine works at muscarinic synapses leading to reversal of ACh excess which reverses the clinical effects of cholinergic excess at parasympathetic end organs. High dose of atropine was given which is well established. Pralidoxime which is recommended by the WHO was given whose main action is to reactivate AChE that has not undergone aging because aged enzyme cannot be reactivated by oximes, thereby recovering neuromuscular transmission at nicotinic synapses.

Gastrointestinal symptoms were most prevalent in our study. We did not find any case of mydriasis. This shows similarity with the study of Madhavan et al. [13]. The mortality rate in the present study is $20.87 \%$, which is much higher in the study conducted by Kora et al. [15], where it was found to be $4.72 \%$. The mortality rate directly depended on the time at which the patient received the treatment and in one study, it was $47 \%$, because in that study, the treatment was given late [16].

Aluminum phosphide was the second most pesticide poisoning group in our study $(\mathrm{n}=25)$. This is used as rodenticide and pesticide in grain storage facilities. It produces phosphine gas which results in mitochondrial poisoning. There is no specific antidote for this poisoning.

The patients admitted in our hospital were presented with the features of severe hypotension, dizziness, fatigue, tightness in the chest, nausea, vomiting, and headache. Two patients died in our study one due to acute respiratory distress syndrome and the other from profound shock and multiorgan failure. The delay in arrival might be the cause of their death. Although all the patients were treated with $\mathrm{MgSO}_{4}$ and antacid after gastric lavage with $\mathrm{KMnO}_{4}, 23$ patients survived. This study agrees with the study conducted by Singh et al. (1997) [17].

Cypermethrin is a synthetic pyrethroid used as an insecticide in largescale agricultural application as well as for domestic purposes. In large doses, it may produce neurotoxicity such as tremor, fasciculation, convulsion, coma, and even respiratory failure [18]. It causes type 1 hypersensitivity reaction like anaphylaxis when exposed to the mouth, lips, eyes, or skin. ECG may show ST-T changes, sinus tachycardia, and ventricular premature beats [19]. It also causes increased salivation, upper gastrointestinal bleeding, and rarely renal failure.

In our study, the patients were presented with the symptoms of facial burning and tingling, dizziness, nausea, and headache. One patient died with seizure.

Glyphosate is a non-selective herbicide which is absorbed from the gastrointestinal tract. Multiorgan dysfunction including hypotension, kidney or liver dysfunction, pulmonary edema or pneumonitis, altered level of consciousness, and/or metabolic acidosis is associated with severe glyphosate poisoning [20]. This study observed symptoms of nausea, vomiting, erosion of gastrointestinal tract, dehydration, hypotension, pneumonitis, altered level of consciousness, hyperkalemia, and dysrhythmia in patients of glyphosate poisoning. Two out of 10 patients died of this poisoning, both with multiorgan failure. Patients developing acute kidney injuries, hyperkalemia, pulmonary edema, and metabolic acidosis are more likely to die [21].

Oleander poisoning patients brought to our hospital showed the clinical features of vomiting, abdominal pain, drowsiness, dizziness, syncope, palpitation, bradycardia, and hypotension with 4 asymptomatic cases. ECG findings showed sinus bradycardia in eight patients and first degree AV block in six patients with no other abnormalities. All of them responded to atropine and orciprenaline. No casualties were found in our study. Mild ingestion and early intervention might be the cause of above result.

The symptoms of benzodiazepine poisoning may include drowsiness, slurred speech, nystagmus, hypotension, ataxia, coma, respiratory depression, and cardiorespiratory arrest [22]. All the patients in our study exhibited the above features except nystagmus, coma, and cardiorespiratory arrest with zero casualties. Drugs were mainly used by males and were not taken in fatal doses.

Two patients with kerosene (paraffin) poisoning were admitted in our hospital, one was asymptomatic while the other was presented with nausea, vomiting, and cough. No casualties were there. However, in the study of Reed et al. [23] and Wolfe et al. [24], kerosene produces CNS excitation in low doses and depression in high doses. Other effects include nausea, vomiting, abdominal pain, hepatitis, acute hepatic or renal failure, and rhabdomyolysis.

Overall mortality rate was $12.5 \%$ in our study with a total number of 25 deaths out of which 19 were from organophosphate poisoning and 3 from rodenticide (aluminum phosphide and norbormide) poisoning and 2 from herbicide (glyphosate) poisoning; thus, all deaths were due to pesticide poisoning. This shows the similarity with the study made by Santosh et al. [3], where the mortality was $8.7 \%$ which was little less than our study with a total of 21 deaths of whom 19 were due to organophosphate poisoning and 2 due to rodenticide poisoning.

\section{CONCLUSION}

This study showed that the most common agents used for deliberate self-poisoning were pesticides followed by plant poison. Among pesticides, organophosphate was the most common poisoning agent followed by aluminum phosphide. The occurrence was mostly among young persons, housewives, and illiterates. Since a large number of deliberate self-poisoning are made with pesticides, due to their easy accessibility, bringing down the morbidity and mortality associated with the same needs legal changes regarding the sale of pesticides.

\section{AUTHORS' CONTRIBUTIONS}

The authors declare that all the named authors have contributed equally to this article.

\section{CONFLICTS OF INTEREST}

The authors have no conflicts of interest to disclose.

\section{FUNDING}

No funding sources.

\section{REFERENCES}

1. Hawton K. Sex and suicide. Gender differences in suicidal behaviour. Br J Psychiatry 2000;177:484-5.

2. Gururaj G, Isaac MK, Subbakrishna DK, Ranjani R. Risk factors for completed suicides: A case-control study from Bangalore, India. Inj Control Saf Promot 2004;11:183-91.

3. Santosh V, Menon O. A retrospective study of clinical profile of acute poisoning in a tertiary care teaching hospital Kerala, India, during 2014-2016. Int J Sci Stud 2018;67-71

4. Eddleston M, Buckley NA, Eyer P, Dawson AH. Management of acute organophosphorus pesticide poisoning. Lancet 2008;371:597-607.

5. Prescott K, Stratton R, Freyer A, Hall I, Le Jeune I. Detailed analyses of self-poisoning episodes presenting to a large regional teaching hospital in the U.K. Br J Clin Pharmacol 2009;68:260-8.

6. Prosser JM, Perrone J, Pines JM. The epidemiology of international non-fatal self-harm poisoning in the United States: 2001-2004. J Med Toxicol 2007;3:20-4

7. Zaidan ZA, Burke DT, Dorvlo AS, Al-Naamani A, Al-Suleimani A, Al-Hussaini A, et al. Deliberate self poisoning in Oman. Trop Med Int Health 2002; 7:549-56. 
8. Waddy S. Management of the poisoned patient. Anesth Intensive Care Med 2007;8:474-6.

9. Sharma BK, Harish D, Sharma V, Vij K. The epidemiology of poisoning: An Indian view point. J Forensic Med Toxicol 2002;19:5-11.

10. Dash SK, Mohanty MK. Sociodemographic profile of poisoning cases. J Indian Acad Forensic Med 2005;27:133-8.

11. Singh S, Shama BK, Wahi P, Anand BS, Chugh KS. Spectrum of acute poisoning in adults (10 year experiences). J Assoc Physician India 1984;32:561-3.

12. Singh B, Kishore K, Chaudhary KA. Epidemiological profile of complete suicidal poisoning cases autopsied at autopsy centre, RIMS, Ranchi. Int J Med Toxicol Forensic Med 2017;7:32-42.

13. Madhavan I, Santhosh LK, Thomas V. Clinical profile and outcome of deliberate self poisoning cases in medical wards. Am J Intern Med 2015;3:5-9.

14. Das RK. Epidemiology of insecticide poisoning at A.I.I.M.S. Emergency service and role of its detection by gas liquid chromatography in diagnosis. Med Legal Update 2007;7:49-60.

15. Kora SA, Dodamani GB, Halagali GR, Vijayamahantesh SN, Umakanth B. Socio-demographic profile of the organophosphorous poisoning cases. J Clin Diagn Res 2011;5:953-6.

16. Siwach SB, Gupta A. The profile of acute poisoning in Haryana-Rohtak study. JAPI 1995;43:756-9.
17. Singh UK, Chakraborty B, Prasad R. Aluminium phosphide poisoning: A growing concern in pediatric population. Indian Pediatr 1997;34:650-1.

18. Podosinovikova NP, Soloveva NE, Mukovskii LA, Petrov VV, Matveev BB, Dolgo-Saburov VB. Pharmacological analysis of the pathogenesis of acute poisoning with the synthetic pyrethroid cypermethrin using the hydrobiont Daphnia magna Straus. Eksp Klin Farmakol 2002;65:56-7.

19. He F, Wang S, Liu L, Chen S, Zhang Z, Sun J. Clinical manifestations and diagnosis of acute pyrethroid poisoning. Arch Toxicol 1989;63:54-8.

20. Roberts DM. Text Book of Adult Emergency Medicine. $4^{\text {th }}$ ed. United Kingdom: Churchill Livingstone Elsevier; 2014. p. 1017-24.

21. Lee $\mathrm{CH}$, Shih $\mathrm{CP}$, Hsu KH, Hung DZ, Lin CC. The early prognostic factors of glyphosate-surfactant intoxication. Am J Emerg Med 2008;26:275-81.

22. Ramrakha P, Moore K. Drug overdoses. Oxford Handbook of Acute Medicine. $2^{\text {nd }}$ ed., Ch. 14. Oxford: Oxford University Press; 2004. p. 791-838

23. Reed RP, Conradie FM. The epidemiology and clinical features of paraffin (kerosene) poisoning in rural African children. Ann Trop Paediatr 1997; 17:49-55.

24. Wolfe BM, Brodeur AE, Shields JB. The role of gastrointestinal absorption of kerosene in producing pneumonitis in dogs. J Pediatr 1970;76:867-73. 